\title{
Articles
}

\section{Reporting suicide in New Zealand: Time to end censorship}

\begin{abstract}
ABSTRACI
New Zealand is unique in its legislative restrictions on news media reporting of suicide, with criminal penalties for breaches. Recently, in response to ongoing controversy about the effectiveness of the law in preventing imitative suicides, the Government announced a review of the relevant legislation, the Coroners Act 2006. This article discusses the history of suicide reporting restrictions in New Zealand, suggests they amount to censorship, and furthermore argues that the suicide media discourse here has not taken account of nuances in suicide research which do not support such restrictions, but do justify voluntary moderation of reporting, in line with comparable OECD countries. Also, it argues that current suicide research is based on an outdated conception of media effects, which does not consider adequately the opportunity for public good messages.
\end{abstract}

Keywords: coroner, guidelines, journalist, media effects, news media, suicide

\section{JAMES HOLLINGS \\ Massey University}

\begin{abstract}
OME KINDS of news media reporting of suicide have been shown to be associated with higher suicide rates (Niederkrotenthaler, et al., 2012; Pirkis, Burgess, Francis, Blood \& Jolley, 2006). While no causeand-effect relationship has been established (and it is unlikely an ethical experiment could be designed which would show one), the evidence that certain types of reporting can produce an imitative effect is now widely accepted by the suicide research community (Sisask \& Värnik, 2012). The body of evidence that has emerged since the first studies in the 1970s has supported a push in many countries for moderation of news media reporting of suicides,
\end{abstract}


to minimise the risk of 'copycat' events. Several countries, mainly in Europe, have persuaded the news media to introduce voluntary guidelines in an effort to reduce the kinds of sensationalist reporting most associated with the risk of imitative suicides (Skehan, 2006).

New Zealand and Norway took a stronger line, adopting statutory provisions regulating what could be reported about suicide and when. Norway abandoned this approach, in favour of voluntary guidelines some years ago (UKPC, 2008). New Zealand, on the other hand, has maintained and strengthened statutory restrictions on suicide reporting, despite periodic protests from news media, some coroners and some members of the public, and is now thought to have the most restrictive laws on media reporting of suicide in the world (Pirkis, 2010). This article discusses the history of suicide reporting restrictions in New Zealand, and suggests the suicide media discourse here has not taken account of nuances in suicide research which do not support reporting restrictions, but do justify voluntary moderation of reporting, in line with comparable OECD countries. Also, it argues that current suicide research is based on an outdated conception of media effects, which does not consider adequately the opportunity for public good messages.

\section{Origins of censorship}

New Zealand's restrictions on suicide reporting had their origins in the 1951 Coroners Act. Section 21 allowed the coroner, at the commencement of inquests into deaths that may have been self-inflicted, to direct no reports of the proceedings be published until after the hearings. Introducing the Coroners Bill, Attorney-General Sir Clifton Webb told Parliament that the restrictions embodied a principle laid down in 1821 by the High Court that 'in the interests of justice, decency, order, or even from a consideration of what is due to the family of a deceased, a coroner may hold the whole or a part of the hearing in private'. He added that this power was very rarely exercised.

While the legal rationale for this section appears to have been largely driven by privacy reasons, there was some discussion in the House about the public safety rationale for it. Sir Clifton advised the House that as early as 1936 that the Wright departmental committee on coroners had heard evidence from chief constables, a Dr Roche Lynch, and the Trades Union Congress that publication of details of a suicide was harmful and could lead to imitative cases (Hansard, 1951).

PACIFIC JOURNALISM REVIEW 19 (2) 2013137 
While Sir Clifton may have envisaged this power being rarely exercised, by the 1980s this view had clearly changed. A new Coroners Act was passed in 1988, which effectively introduced censorship of news media reporting of suicide. Although the Act did not use the term censorship, it effectively did just that. A censor has been defined as 'an official who examines material that is to be published and suppresses parts considered offensive or a threat to security' (Soanes, Stevenson, \& Pearsall, 2004). Section 29 (an update of section 21) of the Act banned reporting any particular relating to the manner of death where there was 'reasonable cause to believe that a death ... was self-inflicted', even before the coroner had commenced an inquest (Parliament, 1988). According to the influential media law text Media Law in New Zealand (Burrows, 1990), the Act effectively banned reporting of suicides as suicides, even before the coroner had ruled, and afterwards only as far as permitted by the coroner. Burrows advised that any breach of the Act would amount to contempt of court, which he defined as effectively a criminal offence (Burrows \& Cheer, 2010). In line with Burrows' interpretation, the Act was generally given a conservative interpretation by the news media. As a result, reports of suicides, before inquests had been held, virtually disappeared from newspapers, to be usually replaced by brief items. A common strategy was using euphemisms such as 'There are no suspicious circumstances and the death has been referred to the coroner'. News media were free to report on inquests, however, unless the coroner suppressed details.

The Act coincided with an increase in research on suicide prevention overseas and in New Zealand, particularly through the formation of the Canterbury Suicide Prevention Project, and a heightened awareness in the international medical and general community of the risks of media reporting of suicide. From the 1990s onwards, many countries introduced voluntary guidelines for media reporting of suicide, which reflected research suggesting that sensationalist media reporting (use of large headlines, page one display, graphic photos and description of methods, excessive repetition, glorification) were all risk factors (Etzersdorfer \& Sonneck, 1998). Austria introduced guidelines in the 1990s, with considerable success in moderating media sensationalism (Niederkrotenthaler et al., 2010), and many other European countries followed, as did Australia (Mindframe, 2009). These guidelines generally promote restrained presentation of suicide stories, avoidance of glamorisation and urge journalists to seek context. The Australian guidelines have also had a

138 PACIFIC JOURNALISM REVIEW 19 (2) 2013 
good uptake from the news media (Skehan, 2006). New Zealand was one of the early adopters of this voluntary guideline approach: in 1999 the Ministry attempted to promulgate modifications to reporting on suicide through the use of voluntary guidelines. These guidelines sat alongside the legislative restrictions in the Coroners Act 1988, and unsurprisingly, given the level of legislative restriction already in place, were not widely used by the news media, who also felt they had not been properly consulted on their content (Tully \& Elsaka, 2004). One study found that their uptake was hampered by the fact that journalists tended to conflate the guidelines and the legislative reporting restrictions (Pirkis, 2010).

In 2006 New Zealand moved to tighten its legislative restrictions on media reporting of suicide still further. It passed a new Coroners Act, with a new provision that the only ground on which coroners could authorise the release of details of a suicide was if they were sure public safety was not at risk. It also changed the wording of the relevant section on reporting, from a ban on reporting anything on the 'manner' of death, to a ban on reporting the 'particulars'. The intention, as subsequently interpreted by the Chief Coroner, was to make it explicit that any report that a death was a suspected suicide was forbidden until the inquest had been held, and afterwards only if the coroner specifically allowed it. The Chief Coroner made it clear that 'particulars' included the name, manner of death, and even the fact that a suicide was suspected (Roundtable, 2011).

The Act also ensured the prohibition on news media coverage extended to family members. It made it an offence, subject to a $\$ 1000$ fine, for anyone to make public the details of a suicide without the coroner's permission.

The select committee considering the 2006 Bill received a number of submissions. News media, long unhappy with the 1988 Act, took the opportunity of the first look at the law on suicide reporting since then to try to get the ban lifted. They argued the ban was against current international practice, an unreasonable inhibition on free speech, and the evidence of the risks did not justify such restrictions. One coroner, Garry Evans (2006), of Wellington, made a similar submission, arguing for the importance of openness in reporting suicide: 'Concealment of evidence from the community disempowers it in dealing with the problem'. (Evans, 2006). (NZLR, 1986; Tesoriero, 2006).

The committee also heard submissions supporting the ban. Dr Annette Beautrais, of the Canterbury Suicide Project, argued there was an 
increasing body of evidence that suggested media portrayal of suicide should be in accordance with guidelines recommending muted and cautious coverage, to minimise the risk of suicidal behaviour in vulnerable individuals. She summarised evidence that unrestricted reporting of suicides produced a 'copycat' or imitative effect, and restrictions on, or 'muting' of media reporting could reduce or eliminate this effect. Further, the impact on bereaved families was such that whenever possible, reporting should be limited to the name, address, and occupation of the deceased and the fact the death was self-inflicted (Beautrais, 2005).

In summarising these submissions, the Ministry of Justice considered concerns about whether the prior restraint on publication was justifiable under the Bill of Rights Act, 1990, given the importance of the principle of open justice. It said Crown Law Office advice was that prior restraint was justified in some cases, especially where there may be 'an identifiable risk of harm-the reporting of self-inflicted death is a special case' (Tesoriero, 2006). It based its consideration on whether there was a risk of harm on a summary of the research evidence in Suicide and the Media: Pitfalls and Prevention (Crane, Hawton, Simkin, \& Coulter, 2005). Here is the Ministry's summary in full (with original bolding and underlining):

i. Media reporting or portrayal of suicides can influence suicidal behaviour, leading to: increase in the overall number of suicides, and increases in the use of particular methods of suicide. The degree of influence is still being measured, although the report noted that in 21 of 30 studies which examined reporting of suicide in newspapers there was evidence of an increase in suicides after the reports (with 10 studies finding a causal link).

ii. In contrast, there is no published evidence to suggest that reporting of suicide reduces suicidal behaviour by others below baseline levels or 'puts people off' attempting suicide.

iii. However, modifications of reporting are possible and can lead to significant reduction in imitative suicidal behaviour.

This summary of the research, while true in broad terms, ignored important nuances. These are discussed further below. It seems the Ministry was either unaware or chose to ignore these, because it concluded:

The Ministry considers that clause 61 [this became S71 in the Act] [be] retained in its current form until such time as there is conclusive

140 PACIFIC JOURNALISM REVIEW 19 (2) 2013 
evidence about whether media reporting on suicide has a positive, negative, or null impact on imitative suicide. (Tesoriero, 2006, p. 18)

It added, in a further report to the Select Committee:

The present presumption ... helps to prevent suicide and to protect the family's privacy. Prior restraint [of reporting before the coroner rules]... is consistent with $\mathrm{MoH}$ suicide prevention strategies of promoting careful, prudent and muted reporting of suicide issues in the media. (James, 2006, p. 2)

As a mitigating factor in the restraint on free speech, it noted that coroners were required to consider the Bill of Rights implications for freedom of expression in each case, and that any coroner's decision not to make public details could be reviewed by a High Court judge.

The 2006 Act did not resolve the on-going concern in New Zealand about media reporting. If anything, it inflamed it. Some coroners, including the Chief Coroner, have since called for more openness in reporting of suicide (Fairfax, 2012a). This has been criticised by some suicide researchers, who say it risks causing copycat suicides (Beautrais, \& Fergusson, D.M., 2012). In 2010, the Ministry of Health made another attempt to introduce voluntary media reporting guidelines. This time it did consult the news media, and voluntary guidelines were agreed in 2011. But while the new guidelines now have the backing of the news media, they have been criticised in turn by several New Zealand and international suicide researchers, this time for not consulting suicide academics adequately, and misrepresenting and marginalising research evidence on the risks of suicide reporting. One prominent New Zealand researcher, Professor David Fergusson, believes the Ministry of Health has mismanaged the whole introduction of guidelines (Fergusson, 2013). There is some evidence that the new guidelines have had some effect, as stories about suicide, where it can be reported, with permission from the coroner, now often display messages about how vulnerable individuals can get help (e.g. Hollingsworth, 2012).

In 2012, the Minister for Courts, Chester Borrows, announced a review of the Coroners Act. This was mainly on procedural issues, but he agreed to accept submissions on the issue of media reporting of suicide. In 2013, it was announced that the Law Commission would be asked to review the issue of media reporting of suicide, with a brief to report by March, 2014. 


\section{Arguments for and against the removal of the legal restrictions.}

New Zealand's suicide rate has followed the general trend downwards reported in most OECD countries since 1995. The overall rate in 2010 was $11.5 / 100,000$ (OECD, 2011). While this crept up to $12 / 100,000$ in 2012 , it was still close to the 2010 OECD average of $11.3 / 100,000$. This figure is higher than countries with a traditionally low rate (e.g. UK at 6.2/100,000, Australia 7.8/100,000) but about the same as Ireland, and lower than France (13.8) Switzerland (14.3) and Japan (19.7) (OECD, 2011). However, within this broad picture, there are areas of considerable concern. New Zealand's female youth suicide rate is the highest in the OECD, and the male youth rate the third highest (Health, 2012).

There is a growing body of evidence suggesting that certain kinds of media portrayal of suicide may provoke an imitative effect among vulnerable individuals. A recent summary of 72 known studies concluded:

The vast majority of these studies provide support for the above hypothesis [that media reporting of suicide can lead to copycat behaviours] suggesting that reporting of suicide can result in imitation acts, particularly if the story is prominent, involves explicit descriptions of the suicide method, and it is framed in a way that glorifies the death. (Pirkis, 2010)

On the face of it, this would appear to justify New Zealand's current legislative regime around reporting of suicide. However, there are important methodological factors which need to be taken into consideration. These include the size of the risk, the type of reporting, and the occluding effect of censorship on the public discourse around suicide. Taking each of these in turn:

\section{The size of the risk}

While there appears to be strong evidence of a correlative effect, the size of the effect is small compared to other psycho-social factors (Niederkrotenthaler, et al., 2010). A common estimate is that the risk is around 5 percent of the total risk factors (Hollings, 2012). Thus censorship should not be seen as a silver bullet; any impact of it on suicide rates is likely to be small. All OECD countries that have achieved substantial reductions in suicide rates (e.g. Australia, UK) in recent years have done this without censorship. It can only reasonably be concluded that censorship is not a prerequisite of suicide rate reduction.

142 PACIFIC JOURNALISM REVIEW 19 (2) 2013 
Of course, it could be argued that introducing censorship would have resulted in even steeper rate reductions in these countries, and that without censorship, New Zealand's rate would be higher. And it does not mean censorship may not be justified, as even a small effect may save lives. One estimate of the impact of media reporting of celebrity suicide in New Zealand, based on recent effect size estimates and the population here, is that unrestricted reporting of a celebrity suicide would lead to around 10 more suicides per annum, and possibly up to 23 more, if the celebrity was also an entertainer (Niederkrotenthaler, 2013). This is based on the premise that such reporting is likely to be more sensationalist. Presumably this figure would be less if the reporting was moderated by guidelines.

\section{The type of reporting}

Most of the studies showing a significant effect of suicide reporting on rates have been in countries with a highly sensationalist tabloid media, but few studies have distinguished between types of media reporting. Those studies which have tried to differentiate between types of reporting suggest it is the treatment, not the content, that may be the problem. In one study in Switzerland, tabloid editors were persuaded to eliminate the more lurid aspects of their coverage, such as dramatic page-one headlines, graphic pictures of the suicide method and dramatic accounts of circumstances of death. They kept much content that would be banned in New Zealand, such as the fact it was a suspected suicide, the name, and the manner of death. Although the number of stories on suicide increased four-fold, the study coincided with a slight reduction in the national suicide rate, from 20.7/100,000 in 1991 to 19.6/100,000 in 1994. The authors concluded: 'This may indicate that it is not the number of articles that matters, but the quality of reporting' (Michel, Wyss, Frey, \& Valach, 2000). A recent study in Austria found more than 70 percent of media reports of completed suicides were not associated with an increase in suicide rates (Niederkrotenthaler et al., 2009). In other words, responsible reporting of suicides is possible without the risk of harm to more than two-thirds of vulnerable individuals. The importance of differentiating between types of reporting is implicit in all media guidelines that have been endorsed by suicide researchers. Invariably, these emphasise the importance of avoiding sensationalism, such as page one placement, large headlines, graphic photos and descriptions of method, and repetition, especially in the few days following the death. However, a recent large-scale study in 
Australia, which did attempt to measure item quality, found it had no relationship with suicides. The authors noted it could have been due to a small sample in the quality analysis, and added: 'It is counter-intuitive to dismiss the hypothesis that item quality would be likely to have an impact upon the likelihood of a given media item influencing imitation acts' (Pirkis, et al., 2006, p. 2884). In fact, at least some respected suicide researchers believe some kinds of media reporting of suicide are desirable if they can be done in a restrained way (Niederkrotenthaler, 2013; Pirkis, 2013). In particular, reporting that challenges the idea that suicide is a valid response to crisis may be helpful. A recent study found that some kinds of reporting (of cases where people had contemplated but decided against a suicide) may reduce the suicide rate (Niederkrotenthaler, et al., 2010).

The distinction that should be drawn about the quality of reporting is particularly relevant to the New Zealand context. While concerns have been expressed that the New Zealand news media are becoming more sensationalist (Hollings, Samson, Tilley \& Lealand, 2007) it is questionable whether this is actually true. Some early newspaper reporting in The Truth newspaper, for example, was highly-coloured (Yska, 2010). A recent study found the mainstream media's reporting of suicide is mostly of a more conservative type, and avoids lurid headlines, pictures of method and romanticised portrayals of content - the kinds of reporting that studies have associated with increased suicide rates in favour of a more objective style of reporting that concentrates on the basic facts (Collings \& Kemp, 2010).

These nuances in the research are not always reflected in New Zealand Ministry of Health summaries of suicide reporting risks, which tend to emphasise the risks of news media reports, with little or no qualification with regard to the kind of reporting most associated with imitative effects. This has tended to skew the discourse in New Zealand, around the risks of media reporting. For example, Goal 5: the Ministry of Health's Suicide Prevention Action Plan:

A large body of international evidence suggests that the way suicide is reported and portrayed in the media may increase rates of suicidal behaviour (e.g., Gould 2001; Hawton \& Williams 2001, 2005; Institute of Medicine 2002; Pirkis \& Blood 2001; Schmidtke \& Schaller 2000; Stack 2005; Sudak \& Sudak 2005). This evidence suggests that media depictions may influence suicidal behaviour in the following three ways.

144 PACIFIC JOURNALISM REVIEW 19 (2) 2013 
1. Imitation: Reporting a method of suicide may lead to imitative or 'copycat' suicide attempts using that method. This result is especially likely if media coverage is repetitive, gives details of methods or highlights the suicide of a celebrity or well-known person. These findings have been produced across different times, places, contexts and cultures (e.g., Hawton \& Williams, 2005; Liu, et al 2007; Phillips, 1974; Sonneck, et al 1994; Yip et al., 2006).

2. Contagion: Media depiction may facilitate contagious behaviour. Specifically, the way in which suicides are reported may encourage further suicides within a population of individuals who are interlinked or interrelated. In turn, contagion may lead to the formation of clusters of suicides or suicide attempts. Many case studies and reviews of suicide clusters report exposure to media influences in those who have died by suicide or made suicide attempts (e.g., Davidson 1989; Gould 1990; Gould, et al 1989; Hazell 1993; Tousignant, et al 2005; Wilkie, et al 1998). Young people, people in institutional settings and indigenous communities are overrepresented in suicide clusters (Earls, et al 1990; Gould, et al., 1990; Hazell 1993).

3. Normalisation: Frequent or repetitive reporting of suicide may encourage the public perception that suicide is a reasonable, understandable and common approach to solving life difficulties (Beautrais, et al., 2004).

All the above evidence clearly suggests the potential for some ways of reporting and portraying suicidal behaviours to influence vulnerable people to make suicide attempts. There is little evidence to suggest that media reports of suicide will reduce population rates of suicidal behaviour or deter people from suicidal behaviours (Crane et al 2005; Hawton and Williams 2001). There is no evidence to suggest that increases in suicide rates or in the use of a particular method following the report of a suicide in the media simply represent suicides that would have occurred later anyway but that have been brought forward in time (Crane, et al., 2005). (Health, 2008)

While the above summary is true in itself, it gives an unbalanced impression as to the risks of media reporting of suicide. It gives the impression that it

PACIFIC JOURNALISM REVIEW 19 (2) 2013145 
is the reporting itself, rather than the presentation of it, that is the main risk. It does not mention that some kinds of reporting may incur little risk. Nor does it mention that New Zealand has very little, if any of the kind of tabloid sensationalism captured in most overseas studies. As discussed above, where research has differentiated between sensationalist and non-sensationalist reporting, the picture is different. It does not point out the effect size is small, and that many comparable countries allow it and have still managed to reduce suicide rates. Its claim there is 'little evidence' on positive effects of media reporting on suicide is misleading; there may not have been any in the suicide field, but that is because no one has looked for it in ways which draw on the substantial evidence in the wider media effects literature on potential positive media effects. These are discussed further below.

\section{Wider consideration of media effects}

Another problem with the current research is that it takes little account of the risks of non-reporting. Suicide researchers have rightly pointed out there is no evidence that reporting of suicide risk factors has a beneficial effect on vulnerable individuals, and that in fact may even be harmful (Beautrais \& Fergusson, D.M., 2012).

However, media suicide research has so far appeared to ignore the potential beneficial effect of publicity about the issue on the wider community, and particularly policy makers. In fact the entire debate around media reporting of suicide appears to have been conducted within a paradigm akin to the earlier hypodermic and magic-bullet models of media communication. Those working with a largely passive conception of media audiences, argued that media effects could be targeted at a precisely defined audience, and exaggerated the capacity of mass media messages to have all-determining effects on social behaviour (Rosenberry \& Vicker, 2009). More recent and sophisticated theories of mass communication, such as agenda-setting, priming and framing, have shown the effect of media intervention on the wider community, by setting the agenda of which issues are considered important, and even how they should be thought about (Scheufele, 2000; Scheufele \& Tewksbury, 2007; Sniderman, 2004). It is argued here that any discussion of the effects of media intervention (such as censorship) needs to consider the wider effects on the entire community. No such effects were considered by the select committee considering the 2006 Coroners Bill. It is worth considering what some of the wider media effects of censorship are (what might be termed the costs of censorship), so they can

146 PACIFIC JOURNALISM REVIEW 19 (2) 2013 
be balanced against the undoubtedly life-preserving benefits which have so far dominated the discourse. What are some of these effects?

\section{a. Censorship inhibits responsible reporting}

The current restrictions effectively eliminate the opportunity for restrained, responsible reporting that may promote discussion of the systemic causes of suicide. Several countries have introduced guidelines for media reporting (e.g. Australia, the UK). These typically arise through consultation with media representatives, and encourage news media to avoid the sensationalist elements described above. Reporting of a suspected suicide as such before an inquest is still allowed, as is moderate reporting of the facts, such as the name and circumstances. Journalists are encouraged to provide a balanced report, avoiding, for example, attribution to a single cause (e.g. a relationship problem) and encouraging them to seek comment from relevant experts. Such guidelines were introduced in Australia around 2000, and their dissemination funded nationally since 2002 . According to one recent study, their uptake by Australian media has been considerable (Skehan, 2006). Two international suicide researchers, Jane Pirkis (2013) and Dr Thomas Niederkrotenthaler (2013), both believe that a voluntary, guideline-based approach to reporting is preferable to New Zealand's legislative approach.

Because the current restrictions in New Zealand effectively ban any reporting of a suspected suicide before an inquest, they effectively mean that nothing is reported until months after the event. Typically, inquests in New Zealand are weeks, but more usually months or even years, after the event. By this time, the news value of the event has reduced, and reports of inquests are usually run in the back pages of a newspaper. This reduces the opportunity for any witnesses to the event with relevant information to come forward in a timely manner. The news media play an important role in helping police source witnesses and gather information. In some cases, where police suspect a suicide, they themselves may not be aware there may be another explanation. A recent case in Australia, where a family contested the police assumption of the suicide of a family member, illustrates this point (Fairfax, 2012b). Under New Zealand law, the family could presumably be prosecuted for discussing the case in public, and face a fine of $\$ 1000$, even though they have legitimate concerns that the death was not accidental.

It could be argued that potential witnesses could simply contact the coroner and give evidence at an inquest. However, often witnesses may not be aware 
that some small piece of information may be relevant. The effect of seeing an issue highlighted in the news media often has the effect of jogging people's memories and encouraging them to contribute to the public discourse. Reporters can also go places and gain evidence the police cannot-particularly in talking to witnesses who may be reluctant to talk to the police. The police have long been aware of this media role and use it to good effect.

\section{b. Censorship distorts the issues agenda}

Another side-effect of censorship, as might be predicted by agenda-setting theory, is that the topic of suicide censorship itself has dominated the discourse, rather than the more significant drivers of suicide themselves. Many studies on agenda-setting have shown that issue salience, usually operationalised as perceived public importance, determines which issues dominate the public agenda (McCombs \& Shaw, 1993). Priming theory-sometimes called second-stage agenda-setting - argues that the portrayal of an issue can guide how those issues are talked about (Scheufele, 2000). Framing theory, and more recently, studies in priming theory, suggest audience responses to those issues can be guided by negative or positive portrayal of the issues (Sheafer, 2007; Sniderman, 2004). With censorship dominating the discourse in New Zealand, a noticeable side-effect has been the lack of discussion of perhaps more significant issues. One suicide researcher put this neatly, albeit unintentionally, in a recent email exchange on the censorship debate:

Media effects on suicide are small and even the best guidelines in the world would only have a small impact on the overall suicide rate. However ... this relatively minor policy issue has taken a disproportionate amount of time to be resolved. We would be far better investing in policy debates about how to reduce rates of depression; how to manage those who arrive in hospital after a suicide attempt; how best to regulate access to methods; etc. rather than continuing to debate how best the media can report suicide. (Fergusson, 2013)

It should be pointed out, however, that Fergusson believes legislation should remain until adequate reporting guidelines are agreed with the news media (Fergusson, 2013).

There is evidence the public would see the kinds of public safety concerns raised by individual suicides as high-salience issues, and therefore give them

148 PACIFIC JOURNALISM REVIEW 19 (2) 2013 
a higher priority as issues worthy of action, if we look at the debate on four other current issues: the road toll, fire safety, child abuse and infectious disease. Undoubtedly the most coverage around these are generated about specific events. Publicity about a series of crashes at known black spots helps focus community awareness that there is a common factor, and has highlighted the need for action, while repeated mention of drink or speed or lack of safety belts as factors in crashes has helped build public awareness of these as important factors in road safety. Firefighters miss few opportunities to mention the protective role of smoke alarms after fatal house fires. Tragically, the extensive coverage of the killing of the Kahui baby twins has raised awareness in the wider community of the circumstances which can lead to such deaths, and the part we can all play in avoiding them. Likewise, widespread coverage of the recent meningococcal epidemic in New Zealand (Health, 2013) has helped raise awareness in the general public of risk factors and the need to get immediate treatment. However, and this is a difficult point for some to accept, the salience of these issues rises when the issue is seen as topical and relevant, and when people can identify with the subject of the story, through what are known as 'human interest stories'. Undoubtedly, the most influential coverage has been around the tragic deaths of specific individuals, such as that of 12-year-old schoolgirl Amanda Crook-Barker from meningococcal disease (Boyer, 2012). While some suicide researchers may understandably see the media demand for topicality and subjectivity as an unnecessary risk to vulnerable individuals, given research which suggests risk is higher in the days immediately following a suicide (Crane, et al., 2005), it is precisely these factors which are likely to increase the salience of the underlying issues in each suicide in terms of the public discourse. By eliminating the ability to report topically (i.e. on recent suicides) and largely eliminating the ability to provide human-interest stories, censorship has occluded a potentially powerful agenda-setting and priming effect. Of course, these points are conjectural, and must be balanced against the known risks of these kinds of stories.

While there is no research in the New Zealand context that provides a framework to balance these risks, there is anecdotal evidence of the cost of censorship. Recently, the parents of a suicide expressed regret they were not made more aware of the risks of helium (Francis, 2011). Coroners have also highlighted concerns with the way health professionals have interpreted the Privacy Act, as factors in suicides (Hollingsworth, 2012). However, preven- 
table risk factors such as these get little publicity because the censorship regime ensures media reporting of the suicides to which they are believed to have contributed is delayed and minimal. This is unfortunate in terms of the public policy debate, as these kinds of high-salience issues, often reported in a negative tone, are likely to have a strong effect in terms of framing and priming the public issues agenda (Sheafer, 2007).

\section{c. Censorship does not equate to privacy}

The select committee considering the 2006 Bill stated that a key rationale for keeping the current restrictions was to protect bereaved families from media intrusion. There are good reasons for this; families of suicides can be more vulnerable to suicide themselves. However, the current restrictions do not effectively promote family privacy. This is because despite the restrictions, news media can and still do approach families. Proscribing the publication of certain details undoubtedly has made it less likely that the news media will take an interest, and thus less likely that many families will be approached. However, in those cases in which they do take an interest, they are just as free to approach the family and publish a story about the death, albeit with certain details omitted. The death in 2012 of the high-profile Wellington lawyer Greg King was one example. King was found dead beside his car, only a couple of weeks after a successful defence of the murder accused in a very high-profile murder case. He left a wife and two young children. His death was front-page news, but was subject to a coroner's order that 'in the interests of decency and personal privacy nothing at all may be reported other than the fact that Mr King is dead and his death has been reported to the coroner. This does not prevent personal tributes being published' (Bain, 2012). There was a small comment from the family, through a spokesperson, but mostly the media respected their privacy and most of the coverage consisted of tributes to King's character and career. Because of the coroner's order, this article is unable to report anything further, although online media not based in New Zealand is unrestricted.

There are no similar restrictions on approaching families who have experienced other kinds of illness or injury-related deaths, such as deaths from disease, car accidents or crime. Why should families of suicides enjoy a special protection? On the surface, this exception may seem kind, but some bereaved families have argued the lack of publicity contributes to a sense of shame (Carville, 2013). Why should a death due at least in part to mental illness be 
more deserving of privacy than one due to meningococcal disease, drowning, a road accident, fire or child abuse? In those cases where families genuinely do not wish to speak to the news media, they are able to refuse, and if they are harassed, may seek redress under the current laws on harassment (Burrows $\&$ Cheer, 2010). This approach has worked reasonably well for all for other kinds of death. While it is laudable to protect bereaved families from unnecessary trauma resulting from media intrusion, why should bereaved individuals with legitimate concerns be effectively retraumatised and disempowered by the legislative prohibitions on their speaking out?

\section{Conclusion: a way forward}

The summary above shows there are good arguments for ending the legislative restrictions on suicide reporting in New Zealand, and replacing them with voluntary restraint. The question is: What kind of voluntary restraint?

New Zealand already has voluntary reporting guidelines, but they are of questionable benefit when so little reporting can be done, and when they do not have the support of suicide researchers here. A better starting point would be the Australian news media guidelines, promoted by the Hunter Institute, in conjunction with the repeal of the current legislative restrictions on reporting. The Australian guidelines have gained good acceptance from news media there, without unduly inhibiting news media reporting of suicide, and have been shown to be not incompatible with a decreasing suicide rate. Similar guidelines in New Zealand would still allow reporting of facts, and meet the goals of allowing public debate about issues raised by individual cases, while minimising the risks of an imitative effect. They would also gain the support of at least some suicide researchers here. Even some of those suicide researchers here who support the current legislative approach do so only until a satisfactory voluntary approach can be agreed on.

Whatever the final form of such voluntary guidelines, it is vital that some form is found that gains the support of news media AND at least some suicide researchers. This is not just to conform to some altruistic notion of consensus. If there is to be more reporting about suicides, journalists will inevitably be approaching suicide researchers for comment and information, and it is important that the latter have confidence that they can participate in a valuable public debate in a way which minimises the risk of harm. Equally, it is important that members of the public and journalists are able to raise issues of legitimate public concern without threat of criminal prosecution. 
On the other hand, this has to be balanced against the likelihood that some relaxation of the current legislation may risk an increase in suicides, particularly in the event of a celebrity entertainer suicide. Ultimately, however, this is a risk other countries are willing to take, in the interests of a wider and fuller debate about suicide. While the benefits of such a debate have not been quantified in numerical terms of the impact on suicide rates (and are probably unquantifiable), there are good theoretical and practical arguments, and plenty of anecdotal evidence, that such a debate is worth having in and of itself.

Taking all the above into consideration, it seems more prudent to err on the side of overseas experience and allow modest, guideline-based reporting, rather than conduct what is effectively an uncontrolled experiment on the benefits of near-total censorship.

\section{References}

Minute of Coroner Wallace Bain: In the matter of an inquiry into the death of Gregory James King (Coroners 2012).

Beautrais, A. (2005). Submission to the select committee on the Coroners Bill. Christchurch: Canterbury Suicide Project.

Beautrais, A., \& Fergusson, D.M. (2012). Media reporting of suicide in New Zealand: 'More matter with less art'. New Zealand Medical Journal, 125 (1362).

Boyer, S., \& O'Callaghan, J. (2012). From rash to death in two hours. Stuff. Retrieved August 21, 2013, from http://www.stuff.co.nz/dominion-post/news/7613375/Fromrash-to-death-in-two-hours

Burrows, J. (1990). News media law in New Zealand. Auckland: Oxford University Press.

Burrows, J., \& Cheer, U. (2010). Media law in New Zealand. Wellington: LexisNexis. Carville, O. (2013). Teens' mothers united in grief. Timaru Herald. Retrieved August 21, 2013, from http://www.stuff.co.nz/timaru-herald/news/9094497/Teensmothers-united-in-grief

Collings, S. C., \& Kemp, C. G. (2010). Death knocks, professional practice, and the public good: The media experience of suicide reporting in New Zealand. Social Science \& Medicine, 71 (2), 244-248.

Crane, C., Hawton, K., Simkin, S., \& Coulter, P. (2005). Suicide and the media: Pitfalls and prevention. Crisis: The Journal of Crisis Intervention and Suicide Prevention, 26 (1), 42-47.

Etzersdorfer, E., \& Sonneck, G. (1998). Preventing suicide by influencing mass-media reporting: The Viennese experience 1980-1996. Archives of Suicide Research, $4(1), 67-74$.

Evans, G. (2006). Submission to the Justice and Electoral Committee on the Coroners Bill. Welllington: Ministry of Justice

152 PACIFIC JOURNALISM REVIEW 19 (2) 2013 
Fairfax. (2012a). Coroner calls for more openness of suicide. The Timaru Herald. Retrieved August 21, 2013, from http://www.stuff.co.nz/timaru-herald/suicidetime-to-talk/7111617/Coroner-calls-for-more-openness-of-suicide

Fairfax. (2012b). Family investigation calls suicide into question. Stuff. Retrieved August 21, 2013, from http://www.stuff.co.nz/world/australia/7941749/Familyinvestigation-calls-suicide-into-question

Fergusson, D. (2013). [Email to author].

Francis, C. (2011). Helium suicide sparks call for review. Stuff. Retrieved July 2, 2013, from http://www.stuff.co.nz/national/5484448/Helium-suicide-sparks-callfor-review

Hansard. (1951). Coroner's Bill 1951. Wellington: NZ Parliament.

Health. (2008). NZ suicide prevention action plan 2008-2012: The evidence for action. Retrieved August 21, 2013, from http://www.spinz.org.nz/file/downloads/ $\mathrm{pdf} /$ file $48 . \mathrm{pdf}$

Health. (2012). Suicide facts: Deaths and intentional self-harm hospitalisations 2010. Retrieved August 21, 2013, from Ministry of Health http://www.health.govt.nz/ publication/suicide-facts-deaths-and-intentional-self-harm-hospitalisations-2010

Health. (2013). Meningococcal [Disease]. Retrieved August 21, 2013, from Ministry of Health http://www.health.govt.nz/our-work/diseases-and-conditions/meningococcal

Hollings, J. (2012, November 2012). Reasonable restriction or moral panic? The evidence for and against restrictions on media reporting of suicide in New Zealand. Paper presented at the School of Communication, Journalism and Marketing Seminar Series Massey University, Wellington.

Hollings, J., Samson, A., Tilley, E., \& Lealand, G. (2007). The big NZ journalism survey: Underpaid, under-trained, under-resourced, unsure about the future-But still idealistic. Pacific Journalism Review, 13 (2), 175.

Hollingsworth, J. (2012, August 212013 ). Privacy versus patient health under the spotlight. Stuff. Retrieved August 21, 2013, from http://www.stuff.co.nz/timaruherald/suicide-time-to-talk/7918131/Privacy-versus-patient-health-under-spotlight

James, P. (2006). Coroner's Bill: Additional matters raised during consideration of the Coroner's Bill Departmental Report. Wellington.

McCombs, M. E., \& Shaw, D. L. (1993). The evolution of agenda-setting research: Twenty-five years in the marketplace ofideas. Journal of Communication, 43 (2), 58-67.

Michel, K., Wyss, K., Frey, C., \& Valach, L. (2000). An exercise in improving suicide reporting in print media. Crisis: The Journal of Crisis Intervention and Suicide Prevention, 21 (2), 71.

Mindframe. (2009). Reporting suicide and mental illness. A resource for media professionals. Retrieved August 21, 2013, from Hunter Institute http://www.mindframemedia.info/_data/assets/pdf_file/0018/5139/Media-Book-col.pdf

Niederkrotenthaler, T. (2013). [Interview with author].

Niederkrotenthaler, T., King-Wa, F., Yip, P. S. F., Fong, D. Y. T., Stack, S., Qijin, C., 
\& Pirkis, J. (2012). Changes in suicide rates following media reports on celebrity suicide: A meta-analysis. Journal of Epidemiology \& Community Health, 66 (11), 1037-1042.

Niederkrotenthaler, T., Till, B., Kapusta, N. D., Voracek, M., Dervic, K., \& Sonneck, G. (2009). Copycat effects after media reports on suicide: A population-based ecologic study. Social Science \& Medicine, 69 (7), 1085-1090.

Niederkrotenthaler, T., Voracek, M., Herberth, A., Till, B., Strauss, M., Etzersdorfer, E. \& Sonneck, G. (2010). Role of media reports in completed and prevented suicide: Werther v. Papageno effects. The British Journal Of Psychiatry: The Journal Of Mental Science, 197 (3), 234-243.

OECD. (2011). Health at a glance 2011. Retrieved August 21, 2013, from OECD Publishing http://dx.doi.org/10.1787/health_glance-2011-en

Parliament. (1988). Coroners Act 1988. Retrieved August 21, 2013, from Parliamentary Counsel Office http://www.legislation.govt.nz/act/public/1988/0111/latest/ DLM134197.html

Pirkis, J. (2010). Contribution to knowledge about media pofessionals' experiences with reporting suicide. A commentary on Collings and Kemp. Social Science \& Medicine (1982), 71 (2), 249-250.

Pirkis, J. (2013). [Interview with author].

Pirkis, J., Burgess, P., Francis, C., Blood, W., \& Jolley, D. (2006). The relationship between media reporting of suicide and actual suicide in Australia. Social Science \& Medicine, 62 (11), 2874-2886.

Rosenberry, J., \& Vicker, L. (2009). Applied mass communication theory: A guide for media practitioners. Boston: Pearson.

Roundtable. (2011). Reporting suicide: A resource for the media. Developed by the Media Roundtable and adopted by the Media Freedom Committee and the Newspaper Publishers' Association. Retrieved August 15, 2013, from Ministry of Health http://www.health.govt.nz/publication/reporting-suicide-resource-media

Scheufele, D. A. (2000). Agenda-setting, priming, and framing revisited: Another look at cognitive effects of political communication. Mass Communication and Society, 3 (2-3), 297-316.

Scheufele, D. A., \& Tewksbury, D. (2007). Framing, agenda setting, and priming: The evolution of three media effects models. Journal of Communication, 57 (1), 9-20.

Sheafer, T. (2007). How to evaluate it: The role of story-evaluative tone in agenda setting and priming. Journal of Communication, 57 (1), 21-39.

Sisask, M., \& Värnik, A. (2012). Media roles in suicide prevention: A systematic review. International Journal Of Environmental Research And Public Health, 9 (1), 123-138.

Skehan, J., Greenhalgh, S., Hazell, T., \& Pirkis, J. (2006). Reach, awareness and uptake of media guidelines for reporting suicide and mental illness: An Australian perspective. International Journal of Mental Health Promotion, 8 (4), 28-34.

Sniderman, P. M., \& Theriault, S.M. (2004). The structure of political argument and the logic of issue framing. In W. E. Saris \& P. M. Sniderman P.M. (Ed.), Studies in public opinion. (pp. 133-165). NJ: Princeton.

154 PACIFIC JOURNALISM REVIEW 19 (2) 2013 
Soanes, C., Stevenson, A., \& Pearsall, J. (2004). Concise Oxford English dictionary (11th ed.). Oxford: Oxford University Press.

Tesoriero, P. (2006). Coroner's Bill: Departmental report. (Cor/Moj/4). Wellington. Tully, J., \& Elsaka, N. (2004). Suicide and the media: A study of the media response to'Suicide and the media: The reporting and portrayal of suicide in the mediaA resource'. Christchurch: School of Political Science and Communication, University of Canterbury.

UKPC. (2008). Reporting suicide in the media. Retrieved August 21, 2013, from UK Press Complaints Commission http://www.pcc.org.uk/events/pastevents/suicide/ index.html

Yska, R. (2010). The rise and fall of the people's paper. Nelson: Craig Potton.

Dr James Hollings is a senior lecturer in journalism in the School of Communication, Journalism and Marketing at Massey University, Wellington, and is the Journalism Education Association New Zealand (JEANZ) representative on the editorial board of Pacific Journalism Review.

j.h.hollings@massey.ac.nz

\section{A]四 COMMUNICATIONS}

\section{POSTGRADUATEJOURNALISM}

Bachelor of Communication Studies(Hons) offers students either an applied or an academic pathway incommunication studies. Papers and strands include Asia-Pacificjournalism, digital media, investigative journalism, public relations and screen writing.

Master of CommunicationsStudies(MCS) is a postgraduateresearch degrèe offering practical options. Doctorate in Communication Studies (PhD) is a thesis-based research degree granted on the basis of 4 original and substantive contribution toknowledge. TheFaculty ofDesignand Ereative lndustries encourages and supports innovative interdisciplinary research. The School of Communication Studiés has supervising staff whose research interests cover a range of areas encompassing media, politics and ownership, journalism, human communication, newmedia and development, discourse analysis and popular culture.

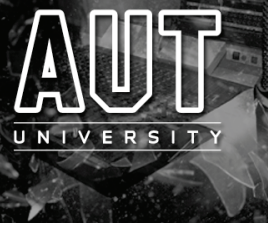

PACIFIC JOURNALISM REVIEW 19 (2) 2013155 